\title{
Influence of super-fine fly ash on the properties of concrete under steam curing condition
}

\author{
Jingjing Feng ${ }^{1, a}$, Lei Yu ${ }^{2, b}$, Yong $\mathrm{Liu}^{3, \mathrm{c}}$, Yang Liü,d and Guodong Ma ${ }^{5, \mathrm{e}}$ \\ ${ }^{1}$ Department of Civil Engineering, Shandong Agriculture University, Taian, 271018, China.

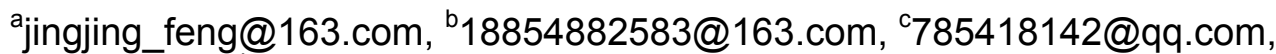 \\ 18854806769@139.com, 'mgd2016@163.com.
}

Keywords: ultrafine fly ash, concrete, compressive strength, porosity, permeability.

\begin{abstract}
The mechanical properties and durability of concrete with or without ultrafine fly ash were studied by measuring the compressive strength and determining the chloride ion penetration and open porosity of concrete. The results show that the addition of ultrafine fly ash reduces the compressive strength at 1 day and can significantly improve the compressive strength of concrete at later ages. The durability of concrete can be enhanced by the using of ultrafine fly ash and lowering the W/B.
\end{abstract}

\section{Introduction}

Precast concrete industry is booming and precast concrete elements are used increasingly in construction due to its advantages [1-3]: reduction in building time, the multiplicity of available products, assured quality with certified performance levels, and so on. The most common method used in precast concrete industry is accelerating curing by means of increased temperature and humidity (steam-curing) [4]. The hydration rate of binder increases with the increasing of temperature, and the gain of strength of concrete can be speeded up under steam-curing condition.

Fly ash from the combustion of coal is industrial by-product that has been widely used as mineral admixture to improve durability and produce high performance concrete for over half a century. The benefits of using fly ash include lowering the heat of hydration, improving the workability, enhancing the durability and decreasing the cracking risk of concrete [5]. The improving effects of ultrafine fly ash on the mechanical properties and durability of concrete are more evident than that of the ordinary fly ash since the fineness can greatly influence the properties of binders.

At present, the steam-cured concrete with high volume ordinary fly ash has been widely studied. But the researches about the properties of concrete containing ultrafine fly ash are scarce. In this paper, the influence of ultrafine fly ash on the properties of steam-cured concrete was investigated.

\section{Experimental}

\subsection{Materials.}

P.I 42.5 Portland cement with a specific surface area of $345 \mathrm{~m}^{2} / \mathrm{kg}$ conforming to Chinese National Standard GB175-2007 was utilized as the main binder in this research. The ultrafine fly ash which was ground to pass the 800 mesh sieve $(15 \mu \mathrm{m})$ was used as mineral mixture. The chemical compositions of cement and ultrafine fly ash are summarized in Table 1. Natural river sand and crushed limestone between 5 and $25 \mathrm{~mm}$ were used as fine and coarse aggregates, respectively.

Table 1 Chemical compositions of cement and fly ash w/\%

\begin{tabular}{cccccccc}
\hline Composition & $\mathrm{CaO}$ & $\mathrm{SiO} 2$ & $\mathrm{Al} 2 \mathrm{O} 3$ & $\mathrm{Fe} 2 \mathrm{O} 3$ & $\mathrm{MgO}$ & $\mathrm{MnO}$ & $\mathrm{SO} 3$ \\
\hline Cement & 63.83 & 21.56 & 4.44 & 2.78 & 2.32 & 2.57 & 3.14 \\
Ultrafine fly ash & 2.86 & 53.33 & 27.65 & 6.04 & 1.35 & -- & 0.45 \\
\hline
\end{tabular}

The mix proportions of the concretes are shown in Table 2. Three mix proportions of concretes were prepared. Sample C was pure cement concrete without mineral mixtures while $20 \%$ of cement were replaces by ultrafine fly ash in sample F1 and F2. The water to binder ratios (W/B) of sample C and F1 were 0.40 while that of sample F2 was 0.37 . The sand ratio of the concrete was 0.42 . 
Table 2 Mix proportions of concrete $\mathrm{kg} / \mathrm{m}^{3}$

\begin{tabular}{cccccc}
\hline Sample & Cement & $\begin{array}{c}\text { Ultrafine } \\
\text { fly ash }\end{array}$ & $\begin{array}{c}\text { Fine } \\
\text { aggregates }\end{array}$ & $\begin{array}{c}\text { Coarse } \\
\text { aggregates }\end{array}$ & Water \\
\hline C & 380 & 0 & 785 & 1083 & 152 \\
F1 & 304 & 76 & 785 & 1083 & 152 \\
F2 & 304 & 76 & 785 & 1083 & 140.6 \\
\hline
\end{tabular}

\subsection{Test Methods.}

Concrete cubes of $100 \times 100 \times 100 \mathrm{~mm}$ were prepared. After casting, samples were pre-cured in a standard curing room with a constant temperature and relative humidity $\left(20 \pm 1{ }^{\circ} \mathrm{C}, \geqslant 95 \% \mathrm{RH}\right)$ for 8 $\mathrm{h}$ and then all specimens were steam cured under the condition of $60{ }^{\circ} \mathrm{C}$ and relative humidity higher than $95 \%$ for $10 \mathrm{~h}$. The specimens were demoulded after natural cooling and placed in standard curing room.

The compressive strength of concrete was tested at the ages of 1, 28 and 90 days. Chloride ion permeability test was conducted at 28 and 90 days in order to determine the resistance of the concretes to penetration of chloride ions according to ASTM C 1202 "Standard Test Method for Electrical Indication of Concrete Ability to Resist Chloride Ion Penetration". The open porosity (accessible to water) of concrete was calculated as:

$$
\begin{gathered}
p_{o}=\frac{V_{\text {water }}}{V_{\text {total }}} \times 100 \% \\
V_{\text {water }}=\frac{m_{\text {sat }}-m_{d}}{\rho_{w}}
\end{gathered}
$$

where $m_{d}$ and $m_{\text {sat }}$ are the dry weight and saturated weight of samples, respectively, $\rho_{w}$ the density of water, $V_{\text {total }}$ the total volume of sample which was measured by the displacement method.

\section{Results and discussion}

\subsection{Compressive strength.}

Fig. 1 shows the compressive strength of concrete with or without fly ash. It can be seen from Fig. 1 that the compressive strength of sample F1 is smaller than that of sample $\mathrm{C}$ at the age of 1 day which can be attributed to the low reaction activity of fly ash at early ages. However, the compressive strength of sample F1 is apparently higher than that of the control sample after curing for 7 days and the strength gap becomes larger with the prolongation of the curing ages. The enhancing effect of ultrafine fly ash on the compressive strength of concrete can be ascribed to the pozzolanic reaction which promoting the hydration of cement, consuming calcium hydroxide $(\mathrm{CH})$ that is a weak part in hydration product, increasing the amount of C-S-H gel and thus improving the microstructure of concrete. Furthermore, the typical particle size of ultrafine fly ash is far smaller than that of the Portland cement and the fine fly ash particles can fill the pores and increase the density of concrete to increase the compressive strength.

In the case of same replacing level, the compressive strength of concrete containing fly ash with water to binder ratio of 0.37 (sample F2) is significantly higher than that of the concrete with a relatively higher W/B (sample F1). It is commonly accepted that lowering W/B makes the concrete much denser and significantly improves the microstructure of the interfacial transition zone and thus increasing the compressive strength of concrete. 


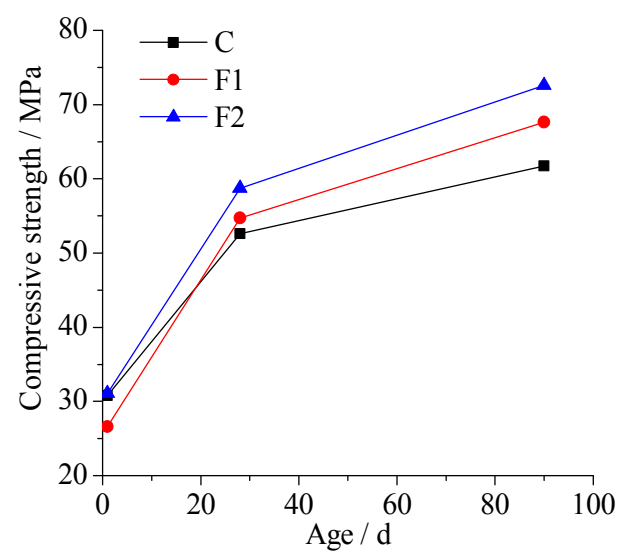

Fig. 1 Compressive strengths of concretes

\subsection{Permeability of concrete.}

Fig. $2 \mathrm{a}$ and $\mathrm{b}$ show the chloride ion permeability of concrete at 28 and 90 days, respectively. According to ASTM C1202, the permeability of concrete falls in the "Very Low" level when the charge passed is between 100 and 1,000 coulombs and falls in the "Low" level when the charge passed is between 1,000 and 2,000 coulombs, while it falls in the "Moderate" level when the charge passed is between 2,000 and 4,000 coulombs. As shown in Fig. 2, the permeability of concrete containing ultrafine fly ash (sample F1) decreases one and two levels compared with that of the pure cement concrete (sample C) at the age of 28 and 90 days, respectively. The experimental result indicates that the resistance to chloride ion penetration of concrete is significantly enhanced by adding fly ash. At the meanwhile, the decreasing of W/B can decrease the chloride ion permeability of concrete especially at early ages since it greatly improve the microstructure of the concrete.

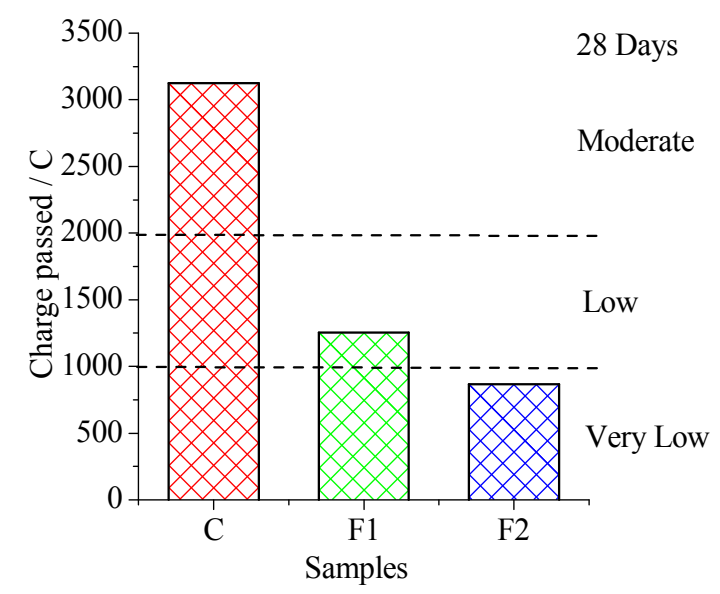

(a)

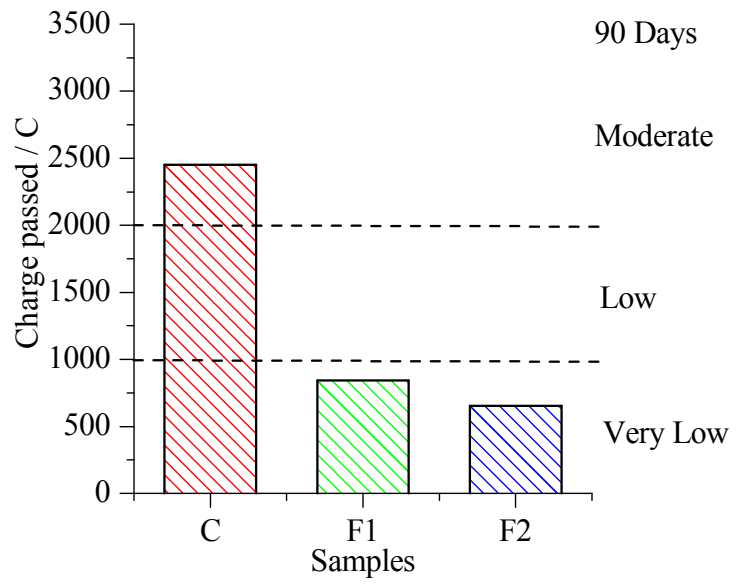

(b)

Fig. 2 Chloride ion permeability of concretes (a) 28 days; (b) 90 days

\subsection{Porosity.}

The open porosity (accessible to water) of concrete is shown in Fig.3. It should be noted that the large pores of the interfacial transition zone make up the main porosity of concrete. It can be seen from Fig. 3 that the decreasing of W/B significantly reduces the total porosity of concrete and the addition of fly ash can slightly reduce porosity at later ages. 


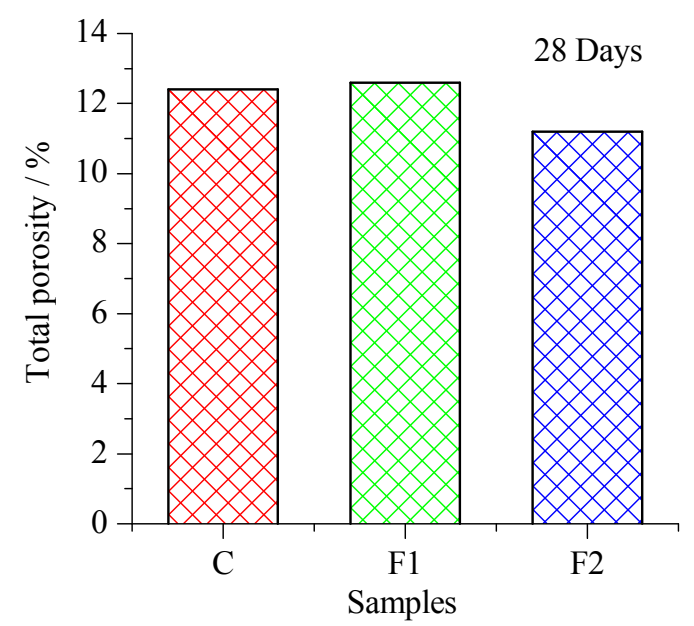

(a)

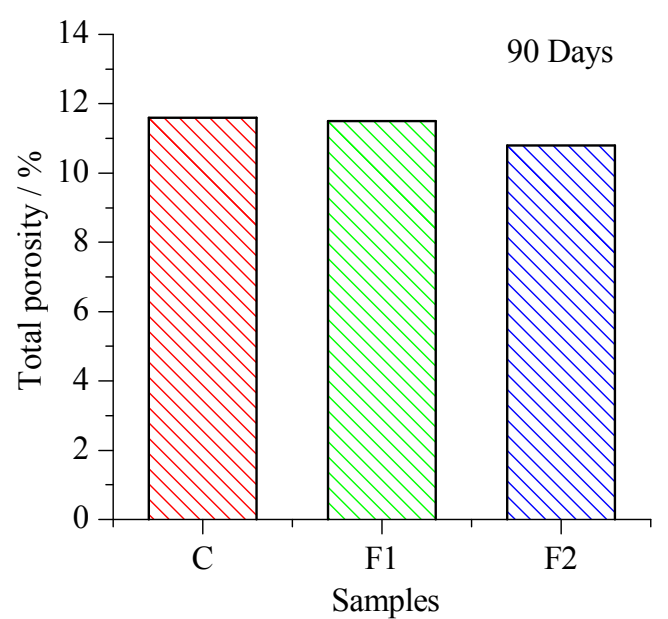

(b)

Fig. 3 Open porosity (accessible to water) of concretes (a) 28 days; (b) 90 days

\section{Summary}

(1) The addition of ultrafine fly ash can significantly improve the mechanical properties of concrete at late ages. The decreasing of W/B can improve the compressive strength of concrete at all ages.

(2) The ultrafine fine fly ash can greatly improve the chloride ion permeability resistance of concrete at all ages. The ability of concrete to resist chloride ion penetration is enhanced by lowering the W/B. The porosity of the concrete is reduced with the decreasing of W/B.

\section{Acknowledgements}

Authors acknowledge the support from Technology Innovation Project of Shandong Agricultural University.

\section{References}

[1]. Cassagnabère F, Mouret M, Escadeillas G. Early hydration of clinker-slag-metakaolin combination in steam curing conditions, relation with mechanical properties. Cement and Concrete Research, 2009, 39(12): 1164-1173.

[2]. Wang Qiang, Li Mengyuan, Zhang Bo. Influence of pre-curing time on the hydration of binder and the properties of concrete under steam curing condition. Journal of Thermal Analysis and Calorimetry, 2014, 118(3): 1505-1512.

[3]. Wang Qiang, Li Mengyuan, Jiang Guohua. The difference among the effects of high-temperature curing on the early hydration properties of different cementitious systems. Journal of Thermal Analysis and Calorimetry, 2014, 118(1): 51-58.

[4]. Shi Mengxiao, Wang Qiang, Zhou Zhikai. Comparison of the properties between high-volume fly ash concrete and high-volume steel slag concrete under temperature matching curing condition. Construction and Building Materials, 2015,98:649-655.

[5]. Liu B, Xie Y, Li J. Influence of steam curing on the compressive strength of concrete containing supplementary cementing materials. Cement and concrete research, 2005, 35(5): 994-998. 